УДК 004.42

DOI: $10.51522 / 2307-0382-2021-235-12-34-37$

\section{МАКСИМ АЛЕКСАНДРОВИЧ БОНДАРЬ}

преподаватель кафедры организации оперативно-розыскной деятельности ФКОУ ВО Кузбасский институт ФСИН России, майор внутренней службы, m.bondar@kifsin.ru

Новокузнецк
MAKSIM A. BONDAR

Lecturer of the Department of Organization of Operational-Investigative Activities of the KI of the FPS of Russia, Major of the Internal Service, m.bondar@kifsin.ru

Novokuznetsk

\title{
Использование 3D-моделирования
}

в программном комплексе «Модели специальной техники УИС» при обучении курсантов Кузбасского института ФСИН России по ведомственной специализации «Оперативно-розыскная деятельность»

The use of 3D-simulation in the software complex «Models of the FPS special equipment» in the training of cadets of the KI of the FPS of Russia in the departmental specialization «Operational Investigation Activity»

Аннотация. Статья посвящена вопросам повышения эффективности учебного процесса в образовательных организациях ФСИН России за счет применения компьютерного моделирования. Предметом статьи выступает 3D-моделирование в программном комплексе «Модели специальной техники УИС». Цель исследования - обосновать высокую теоретическую и практическую значимость данного программного комплекса в преподавании дисциплины (модуля) «Специальная техника».

В результате проведенной работы рассмотрен подход к образовательному процессу при подготовке обучающихся ведомственной образовательной организации с применением программного комплекса, предоставляющего возможность работы с консолидированной информацией, описана структура комплекса, функциональные возможности, отражена его ведомственная специфика, связь с практической деятельностью сотрудников уголовно-исполнительной системы Российской Федерации.

Сделаны выводы о том, что программный комплекс имеет выраженную практическую направленность, так как внедрение 2D-, 3D-моделирования в образовательный процесс повышает эффективность обучения, обогащает обучающихся знаниями в области технических дисциплин.

Ключевые слова: программный комплекс, специальная техника, цифровая трансформация, информационные технологии, обучение.

Abstract. The article is devoted to the issues of increasing the efficiency of the training process in educational institutions of the Federal Penitentiary Service of Russia through the use of computer 
simulation. The subject of the article is $3 \mathrm{D}$-simualation in the software complex «Models of the FPS special equipment». The purpose of the study is to substantiate the high theoretical and practical significance of this software complex in teaching the discipline (module) «Special equipment».

As a result of the work carried out, an approach to the educational process in the training of students of a departmental educational organization with the use of a software package that provides a possibility of work with consolidated information has been considered, the structure of the software complex, its functionality is described, its departmental specifics and the relationship with the practical activities of staff of the Russian FPS are reflected.

It is concluded that the software package has a pronounced practical focus, since the introduction of $2 \mathrm{D}$ - and $3 \mathrm{D}$-simulation in the educational process increases the effectiveness of training, enriches students with knowledge of technical disciplines.

Key words: software package, special equipment, digital transformation, information technology, training.

\section{Для цитирования}

Бондарь M. А. Использование 3D-моделирования в программном комплексе «Модели специальной техники УИС» при обучении курсантов по ведомственной специализации «Оперативно-розыскная деятельность» // Ведомости уголовно-исполнительной системы. 2021. № 12. С. 34-37. https://doi.org/10.51522/23070382-2021-235-12-34-37.

13.00.01 Общая педагогика, история педагогики и образования (педагогические науки)

General pedagogy, history of pedagogy and education (pedagogical sciences)

$\mathrm{B}$ число основных направлений развития современной уголовно-исполнительной системы до 2030 года входят проведение цифровой трансформации и научно-техническое развитие. Данное направление закреплено в Концепции развития уголовно-исполнительной системы Российской Федерации до 2030 года (далее Концепция), утвержденной распоряжением Правительства Российской Федерации от 29.04.2021 № 1138-р [1]. В Концепции определены вызовы, стоящие перед уголовно-исполнительной системой (УИС), закреплены цели и основные направления ее совершенствования.

Роль и место информационных технологий в современном обществе неуклонно возрастают, что обусловлено научно-техническим прогрессом. В связи с этим в последние десятилетия появилось значительное количество новых средств обучения. Яркий этому пример - создание трехмерных моделей, которые активно внедряются в образовательный процесс. Технологии трехмерного моделирования становятся все более значимыми для полноценного развития личности. С активным внедрением современного оборудования в процесс образования у обучающихся появи- лась возможность окунуться в удивительный мир 2D- и 3D-моделей.

Передовым опытом по использованию современных информационных технологий в образовательном процессе может служить создаваемый и тестируемый на учебных занятиях в Кузбасском институте ФСИН России программный комплекс «Модели специальной техники УИС» (далее также - программный комплекс).

Основной целью программного комплекса является формирование профессиональных знаний у обучающихся о возможностях и особенностях специальной техники, используемой сотрудниками в учреждениях и органах УИС.

Программный комплекс предназначен для проведения лекций, семинарских и практических занятий у обучающихся по специальностям 40.05.02 «Правоохранительная деятельность» (программа специалитета) и 40.03.01 «Юриспруденция» (программа бакалавриата) по всем специализациям и направленностям.

Программный комплекс «Модели специальной техники УИС» может функционировать на любой современной операционной системе (Windows, Mac OS, Linux), так как представляет собой веб-приложение. Язык программирования - Python, HTML, C++. 
Внедрение программного комплекса в образовательный процесс способствует решению следующих задач:

- визуальное ознакомление с современной специальной техникой уголовно-исполнительной системы по темам дисциплины (модуля) «Специальная техника»;

- приобретение профессиональных знаний по применению и использованию специальной техники, стоящей на вооружении в УИС;

- формирование познавательной активности обучающихся, творческого мышления;

- приобретение знаний, необходимых для квалифицированного выбора и дальнейшего эффективного и экономически обоснованного применения специальной техники, для решения задач, стоящих перед сотрудниками УИС в соответствии с действующим законодательством;

- использование при организации самостоятельной подготовки по дисциплине (модулю) «Специальная техника».

Программный комплекс «Модели специальной техники УИС» позволяет визуально ознакомиться с современной специальной техникой, состоящей на вооружении уголовно-исполнительной системы. Программа выводится на интерактивные доски, что обеспечивает информационный обмен между преподавателем и курсантом в процессе проведения занятий.

Программный комплекс представляет собой демонстрационный материал, который состоит из 2D-, 3D-моделей специальной техники, схем, таблиц, тактико-технических характеристик специальной техники.

В программном комплексе консолидирован весь материал, который изучается по тематическому плану. Меню программного комплекса имеет простой интуитивный интерфейс и состоит из следующих разделов:

- схемы и таблицы;

- элементы инженерно-технических средств и интегрированных систем безопасности;

- средства связи;

- средства поиска и приборы наблюдения;

- средства фото- и видеосъемки;

- средства звукозаписи;

- специальные химические вещества и иные средства маркировки объектов;
- средства защиты информации.

Применение программного комплекса в процессе преподавания дисциплины «Специальная техника» имеет неоспоримые преимущества перед традиционной формой проведения занятий.

При обычной лекционной форме отсутствует сенсорно-моторный этап восприятия информации. Материал представляется на лексическом уровне с некоторым обращением к символьному этапу (презентации). Когда учебный материал, помимо традиционных форм, представляется и с помощью визуальных образов, в процесс восприятия вовлекаются различные каналы (например, зрение). Это позволяет заложить учебную информацию в долговременную память, ключом извлечения ее служит любой из сигналов, направленный в мозг (например, образ) [2].

Образное визуальное представление специальной техники можно получить путем изучения самого объекта, а также его отображений, полученных с помощью информационных технологий, в том числе в виде электронных 3D-моделей. Важной особенностью трехмерных моделей является возможность изменять свойства как составных элементов модели, так и всей модели в целом, в зависимости от потребностей разработчика. Появляется возможность демонстрации не только статической графики, но и сложной пространственной анимации, а также процессов (в том числе скрытых), проходящих как с объектом, так и внутри него. Это ведет не только к значительному повышению уровня наглядности материала, но и к существенной экономии времени при обучении. Кроме того, современные технологии позволяют получить на основе такой модели фотореалистичную графику, по качеству не уступающую фото- и видеоматериалам.

В отличие от плоских изображений компьютерную 3D-модель можно повернуть на экране под разными углами, рассмотреть с разных сторон (сверху, снизу, сбоку).

Преимущества обучения с использованием информационных технологий в виде применения 3D-моделей очевидны. В отличие от плоских статических изображений такие модели интерактивны: можно выбрать любую точку обзора, сделать любые преобразования, прилагая минимум усилий. Интерактивность компьютерных 3D-моделей означает, что обу- 
чающимся и преподавателям предоставляется возможность активного взаимодействия с данными средствами. По сути, это наличие условий для учебного диалога - взаимодействия, одним из участников которого является компьютерная модель [3].

У обучающихся набора 2016-2017 учебного года в процессе тестирования программного комплекса было проведено анкетирование, направленное на определение эффективности использования данного комплекса при проведении учебных занятий. Анализ показал заинтересованность курсантов в подобных формах обучения. Обучающиеся отметили наглядность, понятность и доступность материала, представленного в программном комплексе.

Очевидно, что разрабатываемый программный комплекс «Модели специальной техники УИС» поможет обучающимся познакомиться с 2D- и 3D-моделированием в образовательном процессе, определит их дальнейшие интересы при использовании специальной техники в практической деятельности в учреждениях и органах ФСИН России.

Основными результатами при использовании программного комплекса должны стать:

1. Для преподавателей:

- сокращение времени, необходимого для объяснения учебного материала;

- рационализация труда с помощью информационно-коммуникационных технологий;

- повышение интереса у обучающихся к предмету.

2. Для обучающихся:
- умение воспринимать информацию;

- развитие пространственного воображения;

- повышение мотивации к обучению;

- умение анализировать;

- облегчение систематизации знаний;

- усвоение большего объема информации, что положительно сказывается на результатах тестов и экзаменов.

3. Для образовательного учреждения - использование инновационных подходов в образовательном процессе.

Таким образом, теоретическая и практическая значимость программного комплекса «Модели специальной техники УИС» определяется возможностью его использования в преподавании дисциплины (модуля) «Специальная техника». Программа данного комплекса имеет выраженную практическую направленность, так как внедрение 2D- и 3D-моделирования в образовательный процесс повышает эффективность обучения, обогащает обучающихся знаниями в области технических дисциплин. Также использование веб-технологий позволяет применять программный комплекс при организации самостоятельной подготовки по дисциплине (модулю) «Специальная техника».

Использование 2D- и 3D-моделей реальной специальной техники УИС - это важное средство для передачи информации, которое служит отличной иллюстрацией при проведении учебных занятий, представлении докладов и презентаций и может существенно повысить эффективность обучения.

1. О Концепции развития уголовно-исполнительной системы Российской Федерации до 2030 года : распор. Правительства Рос. Федерации от 29.04.2021 № 1138-р. Доступ из СПС «КонсультантПлюс».

2. Селезнев В. А., Татаринцева Т. И., Чайкин А. С. Современные информационные технологии в графической подготовке студентов // Вестник Тульского государственного университета. 2012 . № 11. C. $124-128$.

3. Татаринцева Т. И., Селезнев В. А., Жемоедова Н. Л. Виртуальная лаборатория по инженерной графике // Технологии формирования профессиональной компетентности обучающихся в организациях профессионального образования : материалы Междунар. науч.-практ. конф. (2-5 окт. 2013). Брянск : РИО БГУ, 2013. С. 216-219.

1. The concept of development of the penal system of the Russian Federation until 2030 : Ordinance of the Government of the Russian Federation of 29.04.2021 No. 1138-r. Access from Legal Reference System «Consultant Plus».

2. Seleznev, V. A., Tatarintseva, T. I., Chaykin, A. S. (2012) Modern informative technologies in graphic students' preparation // Bulletin of the Tula State University. 11, 124-128.

3. Tatarintseva, T. I., Seleznev, V. A., Zhemoedova, N. L. (2013) Virtual laboratory for engineering graphics // Technologies for the formation of professional competence of students in organizations of vocational education : materials of the Intern. scientific-practical conf. (Oct. 2-5, 2013). Bryansk : RIO Bryansk State University, pp. $216-219$ 